\title{
Inspection of RC half-joint bridges in England: Analysis of current practice
}

\section{Citation:}

P. DESNERCK, J.M. LEES, P. VALERIO, N. LOUDON, C.T. MORLEY (2018) Inspection of RC half-joint bridges in England: Analysis of current practice, IN: ICE Bridge Engineering, 2018

Additional Information:

- Available online as of 18 June 2018

- DOI: $10.1680 /$ jbren. 18.00004

- Additional data related to this publication is available at the University of Cambridge's institutional data repository.

Version:

Accepted for publication

Please cite the published version. 


\title{
Inspection of RC half-joint bridges in England: Analysis of current practice
}

\author{
Pieter Desnerck ${ }^{1,2}$, Janet M. Lees ${ }^{2}$, Pierfrancesco Valerio ${ }^{3}$, Neil Loudon ${ }^{3}$ \\ and Chris T. Morley ${ }^{2}$ \\ ${ }^{1}$ Department of Civil and Environmental Engineering, Brunel University London, London, UK \\ ${ }^{2}$ Concrete and Composites Structures Group, Department of Engineering, University of Cambridge, Cambridge, UK \\ ${ }^{3}$ Structures Policy, Highways England, UK
}

\begin{abstract}
The Strategic Road Network (SRN) in England carries 33\% of traffic in England and Highways England's bridge management systems play a crucial role in the maintenance of infrastructure assets along the SRN. Reinforced concrete half-joint structures are susceptible to deterioration and hard to inspect, hence they require special attention within management programmes. Inspection data relating to half-joint structures on the SRN was gathered. Within this portfolio, 252 structures with half-joint related defects were interrogated to classify the most common defects and identify any potential shortcomings in current inspection practice. Common half-joint defects were related to corrosion and cracking. Clear correlations were shown to exist between defect classes, emphasising the need for quality control and proper workmanship during construction.

A revised inspection methodology for half-joint structures that provides more comprehensive information about crack details, and a greater alignment between defect information and indicators of structural measures, is proposed. A decision-tree approach is used to overcome some of the shortcomings of subjective classifications of the defect cause. Concurrently, knowledge of the zonal crack location, crack orientation and crack severity helps inform the decision-making about the structural condition. There is scope for use of the methodology in conjunction with automated processing procedures to identify half-joint structures with particular defect characteristics and profiles. In this way, asset managers will be better able to allocate resources to structures with an increased risk of failure.
\end{abstract}

Keywords: Bridges; Codes of practice \& standards; Concrete Structures; Corrosion; Field testing \& monitoring; Footbridges; Maintenance \& inspection; Roads \& highways 


\section{Introduction}

The strategic roads network (SRN) in England covers around 4,300 miles. On the basis of length, this represents approximately $2 \%$ of the total roads in England. However, in terms of utilisation, the strategic roads network carries $1 / 3$ of all traffic and $2 / 3$ of all heavy goods traffic (Highways England, 2016b) and hence is a vital economic backbone of the UK. Highways England, formerly known as the Highways Agency, is the government company that is responsible for operating, maintaining and improving England's motorways and major A (trunk) roads.

For structural assets within road networks, management systems have been designed to support structure management activities such as the collection of inventory data, structural inspections and assessments, the management of heavy load transportation, and repair and maintenance activities. These elements all contribute to ensuring traffic safety and maintaining the network at the desired condition through the proper allocation of limited resources (Lauridsen and Lassen, 1999). Asset managers need to maintain their structures such that they are safe for users and remain available for full functional use. Therefore, risks need to be evaluated on two levels: risk in respect of life safety and risk in respect of loss of use. A functional loss can occur as soon as a component of a structure fails and repair works need to be performed (Das, 1999). Different management systems have been developed (depending on local practices and requirements) such as the Danish bridge management system DANBRO (Lauridsen and Lassen, 1999), the Finnish programme (Soderqvist, 1999), AASHTO-Ware (formerly Pontis) developed by the US Federal Highways Administration and AASHTO (Patidar et al., 2007) and the structure management information system used by Highways England (Mirzaei et al., 2012).

On the Highways England road network, regular inspections and maintenance actions are undertaken as set out in the standard BD63/07: Inspection of Highway Structures (The Highways Agency, 2007a). Inspections are carried out by experienced bridge inspectors and engineers employed by the maintaining agents. Guidance on the inspection process is provided by the Inspection Manual for Highway Structures (The Highways Agency, 2007b). The results are recorded in a bespoke structures management information system and are used to guide maintenance activities. 
The data within a given management system is a compilation of information derived from a multitude of sources and gathered by different stakeholders. Visual inspections remain the main source of judgment in current bridge inspection practice all over the world (Enright and Frangopol, 1999), although they are often seen as superficial (McCann and Forde, 2001). Visual inspections are by their nature a subjective process for which the skills, experience and knowledge of the inspector plays a significant role, especially when judging the extent and severity of a certain defect (Kushida, Miyamoto and Kinoshita, 1997; Tarighat and Miyamoto, 2009). Aktan et al (Aktan et al., 1996) state that subjective inspections are one of the most critical technical barriers to effective bridge management. In the United States, it was found that visual inspections show significant variability with a lack of supporting notes, an absence of pictures of specific structural deficiencies and a high variability in condition state assignment (Phares et al., 2004).

For reinforced concrete structures, guidelines have been developed in the UK (The Highways Agency, 1990, 2007a; The Concrete Society, 2007; Collins et al., 2017) and abroad (Ellswoth and Ginnado, 1991; ACI Committee 201, 1997) to provide a reference framework and move towards a more unified outcome of the inspection process. The American Concrete Institute provides a list of reference pictures in their ACI 201.1R-92 Guide for Making a Condition Survey of Concrete in Service (ACI Committee 201, 1997). These images should help inspectors with identifying the type of defect (type and origin of cracks) as well as the width (given as fine, medium and wide). A similar approach is taken by the US Army Corps of Engineers, although drawings are also provided along with pictures. In 2000, the Concrete Society issued the report Diagnosis of Deterioration in Concrete Structures (The Concrete Society, 2000). In this document, they emphasise the importance of the proper inspection and reporting of cracks including the nature and extent of the crack. But, the length, width and orientation should be recorded as well. Reference is made to the work of RILEM TC 104 on Damage Classification of Concrete Structures (Javor, 1991) which provides an example of a classification of crack related defects including severity ratings (Table 1). However, in addition to recording the location, extent, type and orientation of a crack, identifying whether the crack is indicative of current or future structural problems is necessary ( $\mathrm{ACl}$ Committee 224, 2007).

Regardless of the guidance provided and reference documents issued, shortcomings are still reported (Graybeal et al., 2002), e.g. the images in ACI 201.1R-92 may not correspond with what 
can be seen on site (especially in severe weather conditions). A comparison of visual inspections based on different guidelines shows that reports are often vague, uncertain and rely heavily on the inspector's experience, defect definition and damage classification (Tarighat and Miyamoto, 2009).

Table 1: Classification of cracking related defects (after RILEM TC 104 (Javor, 1991))

\begin{tabular}{|c|c|c|c|c|c|}
\hline \multirow[b]{2}{*}{ Damage } & \multicolumn{5}{|c|}{ Damage Rating } \\
\hline & $\begin{array}{c}1 \\
\text { (very slight) }\end{array}$ & $\begin{array}{c}2 \\
\text { (slight) }\end{array}$ & $\begin{array}{c}3 \\
\text { (moderate) }\end{array}$ & $\begin{array}{c}4 \\
\text { (severe) }\end{array}$ & $\begin{array}{c}5 \\
\text { (very severe) }\end{array}$ \\
\hline Cracks in prestressed & Width & Width & Width & Width & Width \\
\hline concrete due to & $<0.05 \mathrm{~mm}$ & $0.05-0.1 \mathrm{~mm}$ & $0.1-0.3 \mathrm{~mm}$ & $0.3-1.0 \mathrm{~mm}$ & $1-3 \mathrm{~mm}$ with \\
\hline overloading & & & & & some spalling \\
\hline Cracks in reinforced & Width & Width & Width & Width & Width $>5 \mathrm{~mm}$ \\
\hline concrete due to & $<0.1 \mathrm{~mm}$ & $0.1-0.3 \mathrm{~mm}$ & $0.3-1.0 \mathrm{~mm}$ & $1-3 \mathrm{~mm}$ with & with widespread \\
\hline overloading & & & & some spalling & spalling \\
\hline Cracks in unreinforced & Width & Width & Width & Width & Width $>25 \mathrm{~mm}$ \\
\hline concrete & $<1 \mathrm{~mm}$ & $1-10 \mathrm{~mm}$ & $10-20 \mathrm{~mm}$ & $20-25 \mathrm{~mm}$ & with spalling \\
\hline Shrinkage or settlement & Single small & Several small & Many small & Few large cracks & Many large \\
\hline cracks & crack & cracks & cracks & & cracks \\
\hline $\begin{array}{l}\text { Effects of reinforcement } \\
\text { corrosion }\end{array}$ & Barely noticeable & Light rust stains & Heavy rust stains & $\begin{array}{l}\text { Heavy rust stains } \\
\text { and cracking }\end{array}$ & $\begin{array}{l}\text { Heavy rust stains } \\
\text { and spalling }\end{array}$ \\
\hline & & & & along line of bars & along line of bars \\
\hline Pop-outs & Barely noticeable & Noticeable & Holes up to & Holes between 10 & Holes $>50 \mathrm{~mm}$ in \\
\hline & & & $10 \mathrm{~mm}$ diameter & and $50 \mathrm{~mm}$ in & diameter \\
\hline & & & & diameter & \\
\hline Spalling & Barely noticeable & Clearly noticeable & Larger than & Areas up to & Areas larger than \\
\hline & & & coarse aggregate & $150 \mathrm{~mm}$ across & $150 \mathrm{~mm}$ \\
\hline
\end{tabular}

Inspection data accumulates over time and is interrogated by various stakeholders to support ongoing decision-making about structures in service. To promote consistency across inspectors' reports and to derive the maximum value from inspections, a transparent categorisation of clearly defined defect types and characteristics is therefore important. A framework that supports the ability to link defect data with indicators of potential criticalities for different categories of structures is also desirable. In the following, these features have been combined within a new approach for data gathering and defect classification that facilitates the interpretation of potential structural consequences due to the nature of the defects. Reinforced concrete half-joint bridges are used as an exemplar and the work draws upon the wealth of experience and information gained through the Concrete Half-Joint Deck Structures Programme managed by Highways England. 


\section{Reinforced Concrete Half-Joint Deck Structures}

Half-joints (also referred to as dapped end beams) are a specific type of joint in which the depth of a beam or slab is significantly reduced at its ends (often to half or even less of the full depth) and is supported by a similar but mirrored cantilevering element (see Figure 1). Half-joints were introduced as a way of simplifying design and construction and the structural form results in a level-running surface. However, half-joint structures are particularly vulnerable to deterioration due to chloride diffusion around the nib when the sealant (at the joint) fails to fulfil its function. As the region where chloride diffusion, and hence chloride-induced corrosion of the reinforcing bars, is largely hidden, inspections and repairs are challenging.
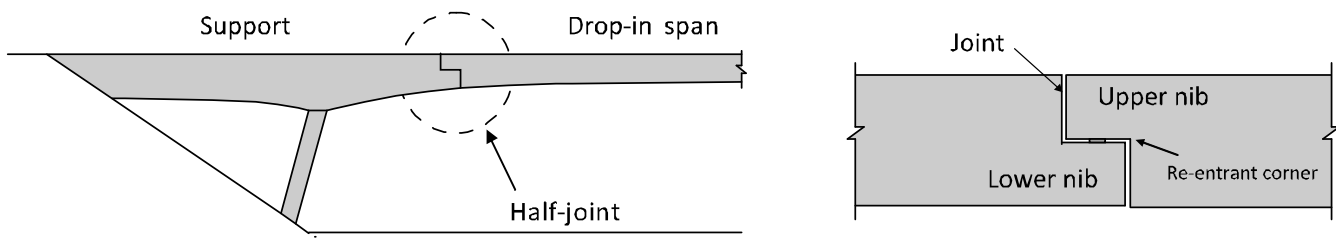

Figure 1: Half-joint principle for reinforced concrete bridges

The behaviour of RC half-joint structures is notoriously complex. Assessment failures can be attributed to the poor condition of the structure and/or non-compliant reinforcement detailing. Experimental work has investigated the impact of the reinforcement layout (Desnerck, Lees and Morley, 2016), detailing, and deterioration (Desnerck, Lees and Morley, 2017b) on the load carrying capacity. It was shown that, in certain cases, synergistic effects greater than the sum of individual defects exist (e.g. the interaction between poor longitudinal reinforcement anchorage and the provision of insufficient shear reinforcement) and lead to substantial strength reductions. Hence, there is a need to identify critical descriptors for existing half-joint bridge assets and their condition, and to ensure that these are clearly chronicled and evaluated during visual inspections. 


\subsection{The Concrete Half-Joint Deck Structures Programme}

In 2004, Interim Advice Note 53 Concrete Half-Joint Deck Structures was published by The Highways Agency (Loudon, 2004) as part of the management strategy for reinforced concrete and steel/concrete composite half-joint deck detailing in suspended span and propped-cantilever bridges. The main objective of IAN53/04 was to ensure that reinforced-concrete half-joint structures were recorded, properly inspected and well managed for the future. The management strategy set out in IAN 53/04, was initially aimed towards data validation and building a full list of all bridge structures with half-joints on the Highways Agency network of trunk roads and motorways. Once the inventory was completed, a stepwise plan (including general and special inspections) was executed to determine the state of each individual half-joint and identify structures that needed further investigation. A systematic approach was taken following welldefined activities.

\section{Processing of Database Data}

An analysis of the data available for reinforced concrete half-joint structures on the Highways England network was performed to gain a better insight into common defects, general trends and geometrical characteristics. The analysed dataset (SMIS, 2016) consists of inspection reports, design drawings, assessments, maintenance records and other related documents linked to the individual structures, combined with additional information obtained from IAN53/04 (Loudon, 2004).

General information about the structure included, amongst other details: the structure name, location (northing, easting, road), description, history (year of construction, year of commissioning), bridge properties (length, number of spans, number of half-joints, tensioning type, original design loading) and typology (structure type, bridge type, carrying type, crossing type). A history of all the inspections undertaken was also compiled, including the date of inspection, inspection category, subcategory according to the half-joint structures programme and potential reason for inspection/comments. A similar list was put together for the assessments. Finally, the defects were processed. The data included the element where the defect was noted, the type, severity and extent as well as comments, potential cause and cause certainty. 


\section{Data Analysis}

\subsection{General observations}

A total of 428 structures with half-joints were identified on the UK Highways England road network (Figure 2) varying from footbridges to highway underbridges or overbidges. The bridges are scattered across the country with a few distinct clusters. Three bridges were demolished as part of an upgrade or end-of-life time consideration, while one bridge collapsed in 2016 after a collision (Highways England, 2016a), so 424 structures are currently still in use.

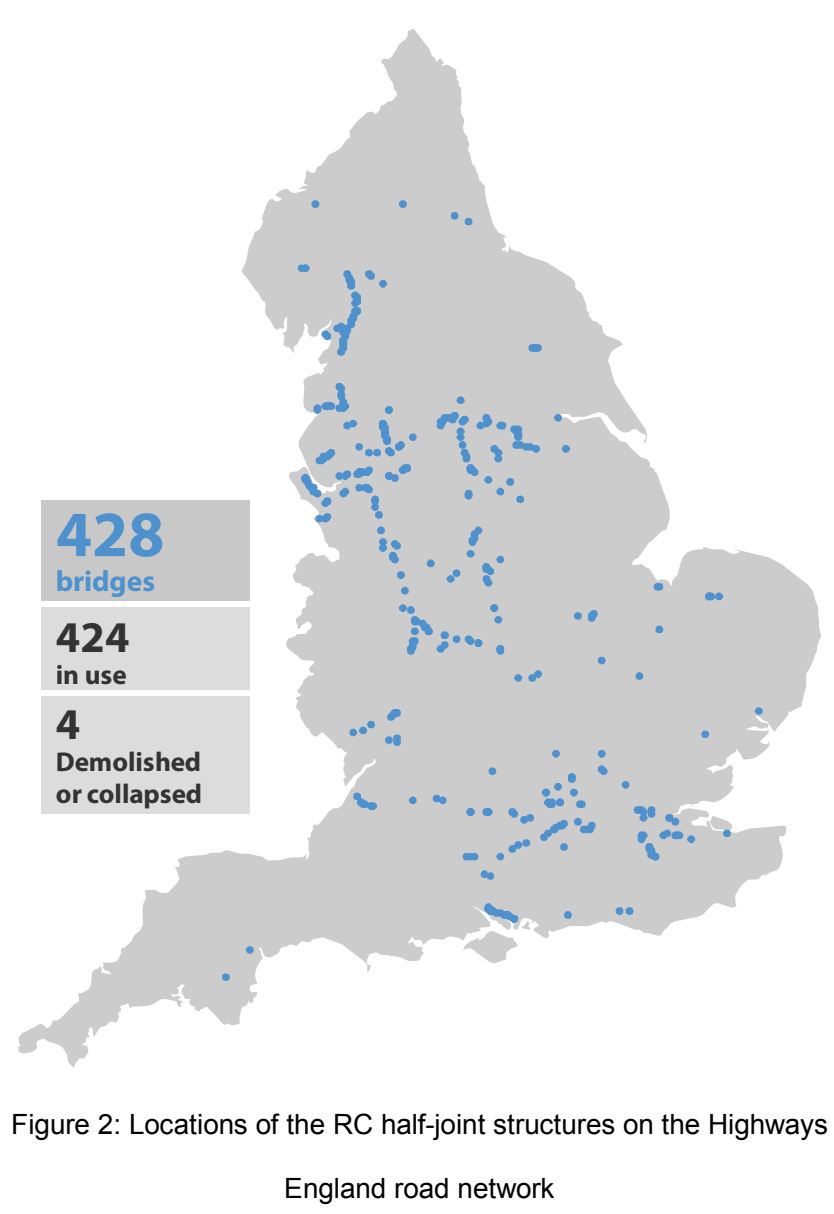

Most of the structures date from the late 1960s and 1970s (see Figure 3) with the first bridge on record built in 1940 and the most recent one in 1989. The length of the bridges varies as there are single span and multi-span structures. The average length, excluding the viaducts, is $72.2 \mathrm{~m}$ and the average number of spans is 4.3 , with a standard deviation of $37.0 \mathrm{~m}$ and 3.6 respectively. 


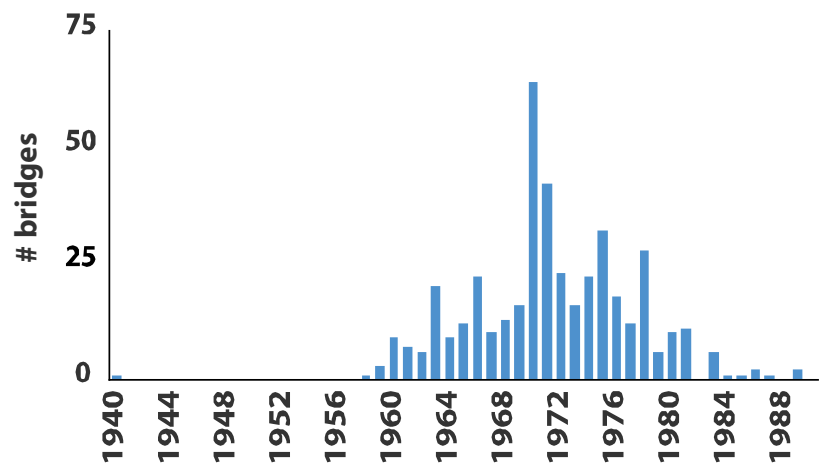

Figure 3: Histogram of year of commissioning of half-joint structures

With respect to construction type, reinforced (23.1\%), post-tensioned $(28.5 \%)$, pre-tensioned structures (31.1\%) and combined pre/post-tensioned bridges $(7.0 \%)$ are in service. There are also bridges for which the tension type is not specified (10.3\%). The primary construction material is in most cases concrete, but in $10 \%$ of structures, the material is either not recorded or of composite steel-concrete construction. Sixteen bridges are along an elevated high load route (3.7\%) adapted for vehicles with 18 or 20 feet running height, while 53 bridges (12.4\%) are part of the heavy load network designed for gross trailer weights of up to 480T.

\subsection{Defects}

Of specific interest is to identify the most common and the most critical defects reported for the half-joint bridges. The existing Highways England database had a predefined list of 172 defects (assumed to be self-explanatory) from which the inspector should select. These defects were then grouped into four broad categories which were either damage-causing, appearance-related, paint/protective systems related or affecting adjoining areas.

As will be discussed, there were some ambiguities within the existing classifications and so there was an opportunity for rationalisation. Furthermore, an additional level of defect classification referred to as 'Defect Group' was introduced to collate predefined commonalities across half joint bridge structures. In the interests of continuity, the existing list of defects was used. However, based on the element with which the defect was associated, a subset of defects that could be linked to the half-joints themselves was extracted. Hence, in the following sections, only those defects related to a half-joint itself will be discussed. 


\subsubsection{Defect Classes}

Each defect was linked to a Defect Class (a redefined broad top-level grouping) which was further subdivided into Defect Groups. The proposed Defect Classes are:

- Aesthetic: all defects that had an impact on the appearance of the structure without further repercussions to the integrity.

- Structural and Deterioration: defects that can be linked to a structural deficiency developed during the lifetime of the structure or having an impact on the structural behaviour/capacity of (an element) of the structure, as well as defects that can be clearly linked to a deterioration process.

- Constructional: defects that can be linked to improper construction methods or flaws in the construction process

- Operational: defects that have an impact on the operational aspects of the structure only

- Other: defects not covered by the previous categories e.g. foreign objects.

\subsubsection{Defect Groups}

The Defect Groups assigned to the proposed 'Structural and Deterioration' as well as the 'Constructional' Class are summarised in Table 2. The Groups combined different defects into clusters based on their similarities or commonalities.

Table 2: Defect Groups for Structural, Deterioration and Constructional Defects of Half-Joint Structures

\begin{tabular}{lll}
\hline $\begin{array}{lll}\text { Constructional } \\
\text { Defects }\end{array}$ & Structural and & \\
\hline Blowholes & Deterioration Defects & \\
Honeycombing & Bond & Impact (Accident) Damage \\
Irregular shuttering & Corrosion & Iron pyrites stains \\
Poor Compaction & Cracking & Mortar \\
Shuttering left in place & Deformation & Peeling \\
& Deterioration Mechanism & Ponding \\
& Distortion & Spair \\
& Efflorescence & Spliting \\
& Fracture & Stalactite/Stalagmite \\
& Grout Loss & Surface Void \\
\hline
\end{tabular}

This grouping process revealed some ambiguities in the current list of defects by which inspectors might be uncertain as to which defect to select. These ambiguities included defects which had identical descriptions but different defect codes, which were assumed to be 'appearance only' but 
had a deterioration cause, or for which it is hard to identify any other effects than on the appearance/aesthetics of the element. With respect to structural aspects, numerous crack related defects were defined. To correctly identify the origin of the crack in some cases an inspector would need a deeper understanding of the structure and potentially need to undertake a more sophisticated analysis. The difficulty in defining the source might even be such that experts have different opinions.

\subsubsection{Analysis of Half-Joint Related Defects - Defect Classes and Groups}

Across all the selected half-joint structures (the 374 for which inspection data was available), 252 had half-joint related defects reported during at least one of the inspections. The majority of those are structures with 'Structural and Deterioration' related issues (219 bridges) or half-joints with 'Aesthetic' defects (139 bridges), as shown in Table 3. Only two structures showed defects classified as 'Other' associated with the presence of a foreign object close to or at the half-joint.

Table 3: Number of structures with defects at the half-joint within each Defect Class (252 bridges)

\begin{tabular}{lcc}
\hline Defect Class & No. & \% \\
\hline Structural \& Deterioration & 219 & $86.9 \%$ \\
\hline Aesthetic & 139 & $55.2 \%$ \\
\hline Operational & 57 & $22.6 \%$ \\
\hline Constructional & 36 & $14.3 \%$ \\
\hline Other & 2 & $0.8 \%$ \\
\hline
\end{tabular}

The interdependency of the half-joint defects as grouped within the proposed Defect Classes is shown in Figure 4. 'Constructional' defects tend to occur in combination with other problems such as 'Aesthetic' defects, but primarily 'Structural and Deterioration' defects. This emphasises the importance of good quality control on the job site during initial construction to avoid structural issues or accelerated deterioration at a later date. In 80 bridges, the reported defects at the halfjoint were purely of a structural nature or deterioration related, while solely aesthetic problems occurred for 22 bridges, indicating that in most of the cases there is an interdependency (or at least a co-existence) of defects from several defect classes.

In a small number of cases ( 7 bridges) defects within each of the 4 main Defect Classes are reported, although for 20 bridges defects with a structural and deterioration, operational and 
aesthetical origin were recorded, as well as an additional 20 bridges with structural and deterioration, aesthetical and constructional issues.

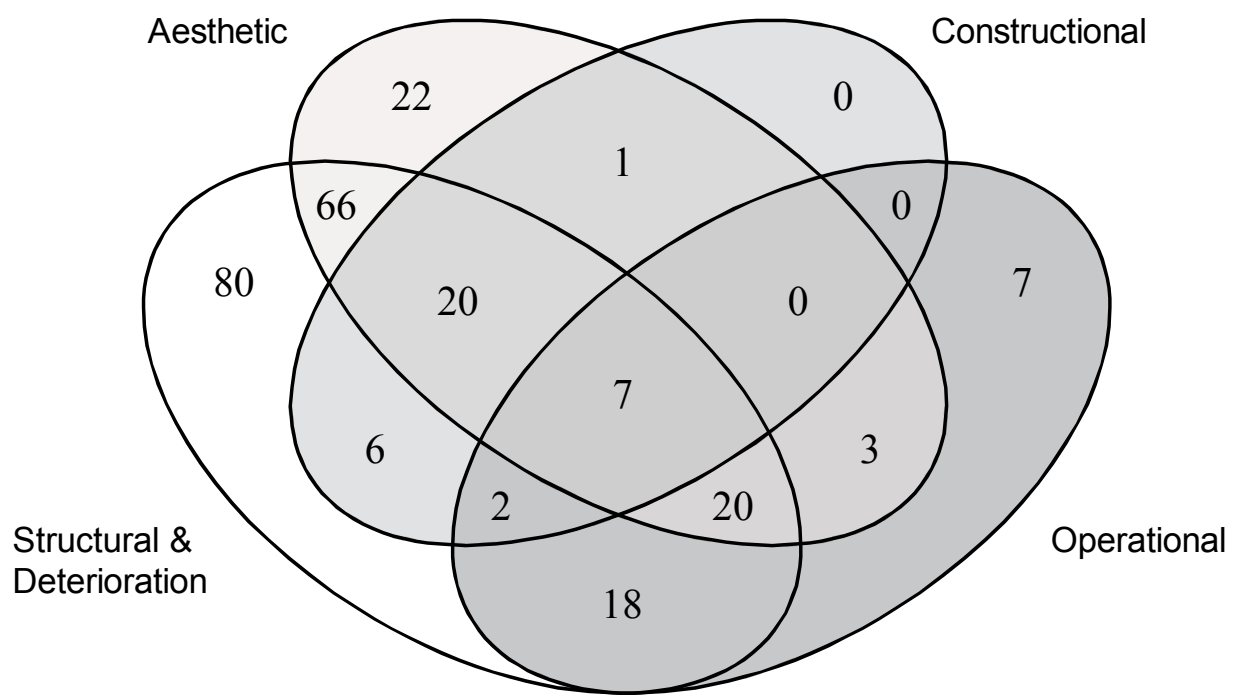

Figure 4: Interdependency of defects classes for structures with half-joint related defects (252 bridges) - numbers represent number of structures within each combination of defect classes

Within the Structural \& Deterioration Defect Class, problems related to the Cracking, Corrosion, Spalling and Deterioration Mechanism Defect Groups were the most common (Table 4). But it should be noted that for $7.3 \%$ of the structures with defects, issues with the repair are reported, indicating that the proper execution of repair works is necessary.

Table 4: Most common structural \& deterioration defect groups for half-joints (219 bridges)

\begin{tabular}{lcc}
\hline Defect Group & No. & $\%$ \\
\hline Cracking & 134 & $61.2 \%$ \\
Corrosion & 84 & $38.4 \%$ \\
Spalling & 76 & $34.7 \%$ \\
Deterioration Mechanism & 73 & $33.3 \%$ \\
Delamination & 46 & $21.0 \%$ \\
Bond & 46 & $21.0 \%$ \\
Stalactite/Stalagmite & 23 & $10.5 \%$ \\
Repair & 16 & $7.3 \%$ \\
\hline
\end{tabular}

The interdependency between Defect Groups is also revealing. About half of the structures with cracking related issues also tend to have corrosion defects (Figure 5), and there is a clear link between spalling and corrosion as was to be expected from our current knowledge of deterioration 
mechanisms. In $57.9 \%$ of structures with reported spalling, some form of corrosion is noted as well (44 out of 76 half-joint bridges). Whereas spalling and cracking are linked for $67.1 \%$ of the structures. Deterioration mechanisms tend to also cause cracking and corrosion problems, while the combination of solely deterioration and spalling is rare.

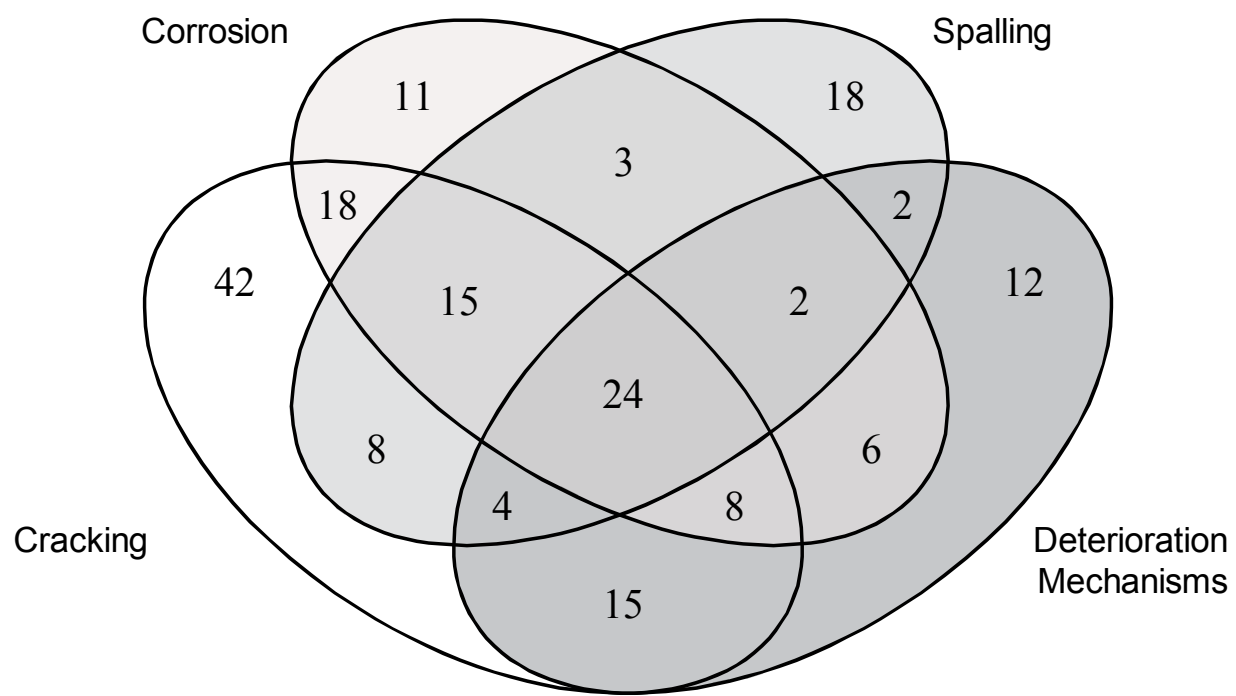

Figure 5: Interdependency of defects groups for structures with half-joint related defects (252 bridges) - numbers represent number of structures within each combination of defect groups

The Defect Group ‘Cracking’ contains 12 different individual defects found in the studied half-joint bridges (Table 5). The data shows that in most cases inspectors indicate a 'Crack of uncertain origin or a combination of causes' or 'Cracked' defect and rarely indicate the cause of the crack. This strengthens the argument made previously that inspectors are possibly uncomfortable with classifying the type of crack and visual inspections can be inadequate as a means of specifying the crack origin. 
Table 5: Number of structures with crack-related defects at the half-joint (134 bridges)

\begin{tabular}{lcc}
\hline Defect & No. & $\%$ \\
\hline Crack of uncertain origin or a combination of causes & 82 & $61.2 \%$ \\
Cracked & 29 & $21.6 \%$ \\
Shear crack & 10 & $7.5 \%$ \\
Reinforcement corrosion crack & 7 & $5.2 \%$ \\
Tension crack & 6 & $4.5 \%$ \\
Flexural crack & 5 & $3.7 \%$ \\
Construction joint crack & 4 & $3.0 \%$ \\
Drying shrinkage crack & 4 & $3.0 \%$ \\
Map cracking & 4 & $3.0 \%$ \\
Early thermal crack & 2 & $1.5 \%$ \\
Frost damage crack & 1 & $0.7 \%$ \\
Crack in mortar only & 1 & $0.7 \%$ \\
\hline
\end{tabular}

\subsubsection{Defect Accuracy and Specification}

A more detailed study of the reported defects was carried out for a randomly selected subset of 23 structures (about 10\% of structures with half-joint related problems). For these structures, the inspection reports were studied in further detail, including the picture evidence provided.

The selected structures are representative of the full set of Highways England half-joints, with not tensioned, post-tensioned, pre-tensioned and pre/post-tensioned reinforced concrete bridges, ranging from footbridge to highway underbridges and overbridges. The oldest structure in the subset is built in 1940, while the most recent structure was constructed in 1978. Two of the structures are on a Heavy Load Route. For the 23 structures a total of 51 principal inspection reports, 75 general inspection reports, 98 special inspection reports and 6 monitoring inspection reports were available. The oldest analysed inspection report dates from May 2002 and the most recent one from June 2015.

In most cases, the reported defect group/class was in line with the visual evidence, although there was some scatter in the specific defect type given the ambiguity that exists between defect codes/descriptions. For a significant number of the defects reported for the selected half-joint cases, pictures were not available or were not sufficiently detailed thereby making verification of the reported defect rather difficult.

In cases with pictorial evidence, some anomalies are noted. Defects are not always allocated to the half-joint itself even though they might be reported for e.g. the central suspended deck or 
cantilever beams and they clearly appear in the disturbed region of the joint (area of discontinuity around the nib in which the hypothesis of Bernoulli is no longer valid). The level of detail provided in the comments section for defects is very variable. Some inspectors do not provide further information about the defect, whereas others include information on crack width, crack length and crack orientation. In a limited number of cases, the type of cracking is specified, e.g. 'Flexural Cracking' or 'Shear Crack', while the location of the crack does not necessarily underpin this classification, e.g. at the inner nib/re-entrant corner (see Figure 1). Even within the same inspection report, a crack originating at the inner nib might be reported as a 'Shear Crack' or a 'Crack of Uncertain Origin or a Combination of Causes'.

Defects are often reported as being related to corrosion while there is also noticeable spalling and cracking in the same area, or vice versa. This, to some degree, undersells the actual state of the structure and might lead to an underestimation of the number of structures with corrosion or spalling issues when only the inputted defect data is studied.

\section{Recommendations for future inspections and data gathering}

An experimental investigation of the impact of deterioration outcomes, improper detailing and substandard reinforcement layouts on the load carrying capacity of reinforced concrete half-joints (Desnerck, Lees and Morley, 2016, 2017a) revealed that, in some structures, individual defects might have a limited impact on the capacity (due to alternative load paths being formed), but that synergistic effects can exist. These synergistic effects can occur when alternative load paths are no longer available when issues appear at multiple locations.

The information derived from bridge inspections should facilitate the identification of structures where such synergistic effects are likely to develop or already occur. By providing clear and robust means for inspectors to map half-joint defects and for this defect-related information to be input into asset management databases, automated systems can then be developed that flag structures which are at risk of becoming substandard in their load carrying capacity. As the most common defects for half-joints were found to be related to cracking, corrosion and spalling, and these types of defects also have the greatest impact on the load carrying capacity, the following recommendations mainly focus on these aspects. 


\subsection{Recommendations}

Based on the results from the analysis of the half-joint data, it was felt that the currently available fields and defect categories do not easily allow for automatic detection of half-joint structures with potential synergistic effects. Rather than relying on limited or sometimes missing information regarding the type of crack, a revised inspection data collection methodology is proposed based on the crack location and orientation. In this way, the subjective aspect of the expert judgement is reduced and more objective data is gathered.

\section{a. Database identification of half-joint specific component or component name}

Each half-joint specific component or element must be defined separately to allow inspectors to allocate detected defects to a specific half-joint. Current databases often rely on the deck/beam component's name to include whether it is a half-joint or not. As discussed, this can lead to the information being scattered and a half-joint related defect being allocated to centre beams or cantilever decks. This reduces the ability of a user to query the database when looking for halfjoint specific information.

\section{b. Defect terminology and decision tree-guidance for Inspectors}

One of the main reasons for scattered and inconsistent data was found to be an ambiguity in defect types and absence of clear defect definitions. Use of the following proposed Defect Groups would help to classify corrosion, spalling and cracking related defects in RC half-joints:

- Corrosion: Exposed reinforcement, Corrosion with loss of section, Rusty nails/Tie wire etc, Rust/stain/spot

- Spalling: Incipient spall, Scaling, Spalled area

- Cracking: Impact (accident) damage crack, Construction joint crack, Crack of uncertain origin or a combination of causes, Drying shrinkage crack, Early thermal crack, Fatigue crack, Frost damage crack, Flexural crack, Formwork movement crack, Mapping crack, Plastic settlement (displacement) crack, Plastic shrinkage crack, Reinforcement corrosion crack, Shear crack, Settlement crack, Tension crack, Crack along line of prestressing tendon, Torsion crack

A glossary with definitions for terms used in the defect names is essential. This glossary can be based on e.g. the International Concrete Repair Institute's Concrete Repair Terminology 
(International Concrete Repair Institute, 2015) or Oxford Dictionary for Construction, Surveying and Civil Engineering (Gorse, Johnston and Pritchard, 2012).

By means of a decision tree based approach inspectors can then be guided towards the selection of the proper defect code within a particular Defect Group. An example of such a tree has been developed for corrosion, cracking and spalling related issues, and can be found in Figure 6.

In this approach detailed guidance for the crack selection is not provided but instead is based on a series of responses to questions. Hence inspectors should only identify the crack type when they feel the origin of the crack is clear and well-known. Otherwise, 'Crack of uncertain origin or combination of causes' should be selected.

\section{c. Data gathering - Inclusion of an overview picture of the inspected half-joint}

An overview picture of a half-joint is a particularly revealing piece of information. Studying close up photos and location descriptions does not always allow for the proper identification of the exact location of a defect within the half-joint. Hence, encouraging inspectors to provide an overview photo and sketch would give an indication of the general condition of the entire half-joint and allow assessors (not involved in the inspection itself), to better understand the state of the half-joint and identify defect locations (in conjunction with the location identification procedures discussed in item d).

\section{d. Data gathering - Zonal identification of the location of the defect}

As discussed previously, an inaccurate or incomplete identification of crack/corrosion/spalling defects can occur. Hence, the acquisition of supplementary crack information based on the crack location and orientation is desirable. The results from the experimental half-joint study mentioned previously (Desnerck, Lees and Morley, 2016), (Desnerck, Lees and Morley, 2017b) were used to identify 6 individual zones within the half-joint which could be indicators of distress. Cracks occurring within a given zone with a specific crack orientation have a higher probability of being associated with a specific issue. 


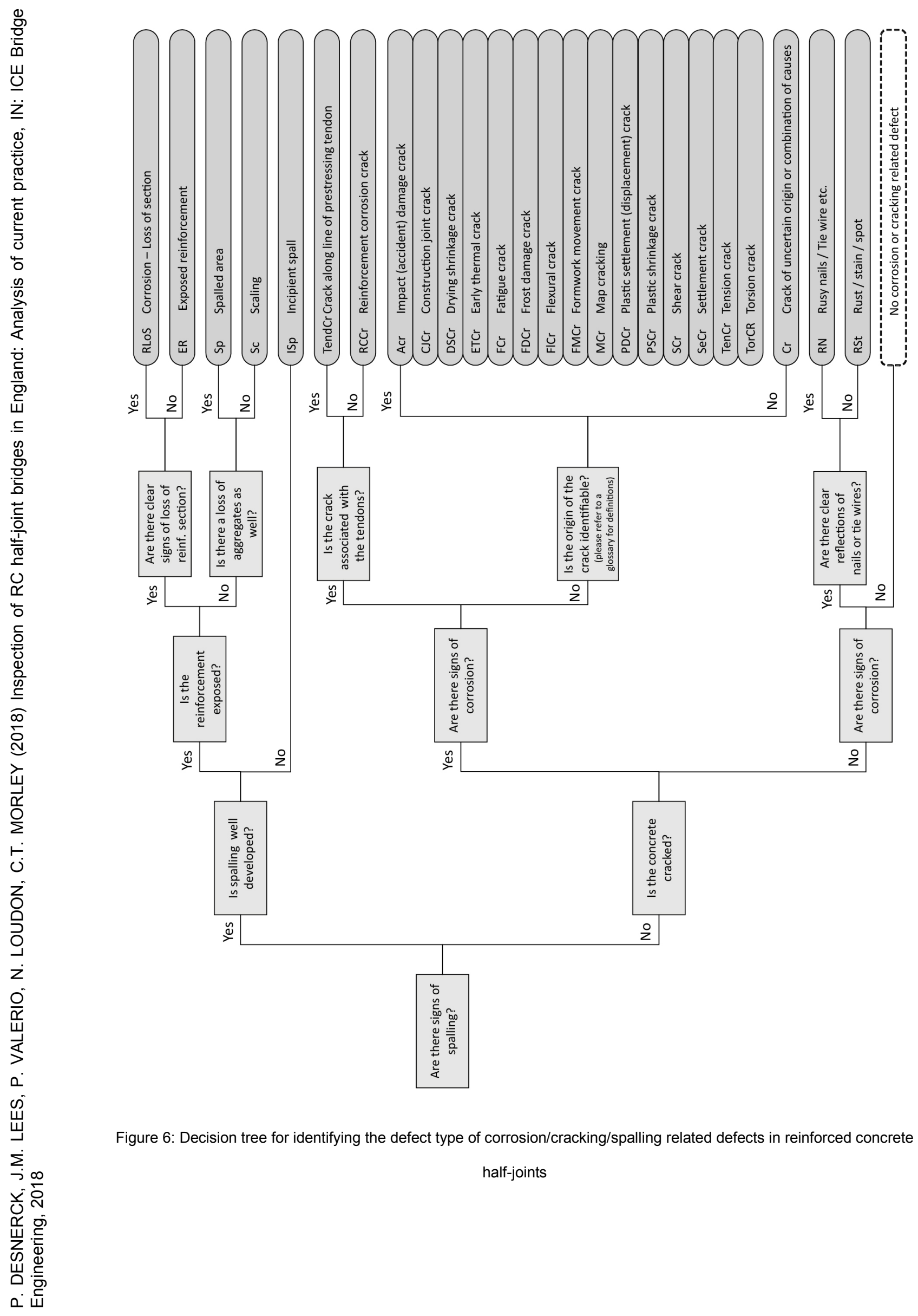


The defined zones are (see Figure 7):

- $\quad$ zone 1: this zone stretches along the compression reinforcement of the half-joint and has a height of two times the reinforcing bar cover $c$. In absence of information on the cover, a value of $2 c=80 \mathrm{~mm}$ can be used.

- $\quad$ zone 2: this zone contains most of the nib of the half-joint. In this zone, the tensile nib reinforcement (often provided by means of a U-bar) is present and anchored.

- $\quad$ zone 3: contains the inner nib region of the half-joints.

- $\quad$ zone 4: the bulk part of the full-depth section of the half-joint forms zone 4.

- $\quad$ zone 5: with a width of $2 c$ (or $80 \mathrm{~mm}$ in absence of detailed information), runs along the face of the full depth section of the beam, and contains the anchorage zone of the tensile reinforcement when these bars have hooked ends.

- $\quad$ zone 6: this zone runs along the tensile reinforcement of the half-joint and has, similarly to zones 1 and 5, a height of two times the reinforcing bar cover. Again, in absence of information on the cover, a value of $2 c=80 \mathrm{~mm}$ can be used.
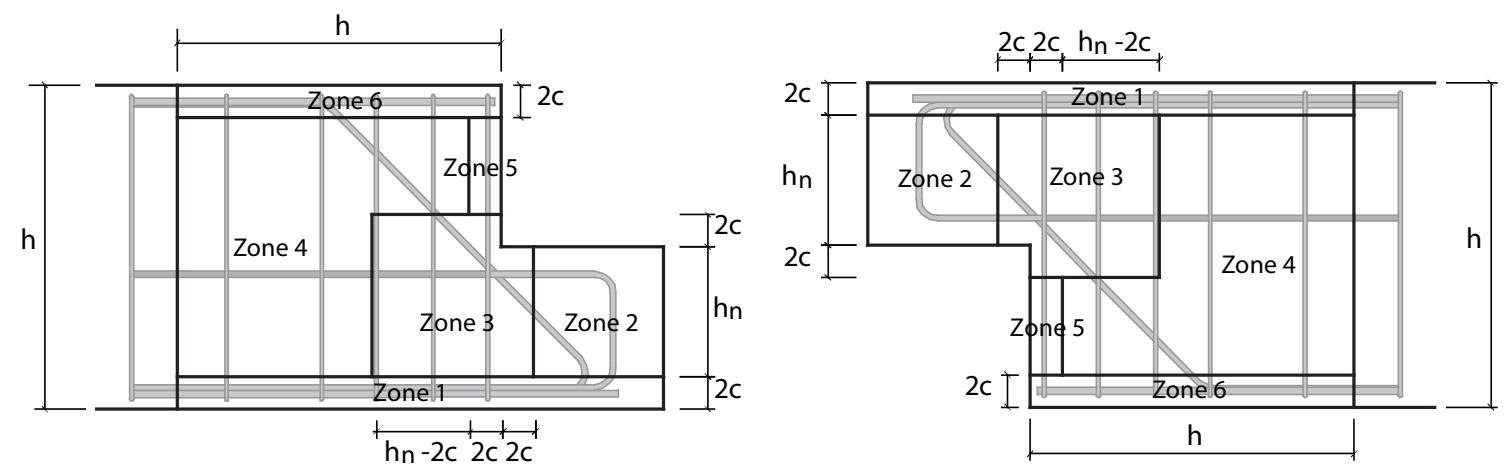

Figure 7: Proposed zonation of half-joint detail to facilitate inspections

\section{e. Data gathering - Crack orientation, severity, extent and width}

In addition to the crack location, the crack orientations should be recorded during inspections. As previously discussed when defining the crack zones, the angle at which cracks are formed can be a significant indicator of the type of defect that is occurring. Most notable are horizontal cracks (crack angle of 0 degrees) which might run along the top and bottom reinforcement or from the inner nib of the half-joint; vertical cracks which can be bending cracks; cracks along vertical 
reinforcing bars (due to corrosion) or inclined cracks that are most likely indicators of shear issues. The options that can be provided for inspectors might be 0 to 20 degrees (mostly horizontal), 20 to 70 degrees (inclined), 70 to 90 degrees (mostly vertical).

The current Highways England database allows for a severity and extent classification of defects. With respect to the extent, the current definitions make a distinction between $0-5 \%, 5-20 \%, 20$ $50 \%$ and more than $50 \%$ of the length or area of the component. Given the creation of the halfjoint zones, expressing the extent as a percentage of the zone area/length might provide an additional level of detail. For cracks, one can even argue that the extent class of $0-5 \%$ is rather insignificant and a distinction needs to be made between cracks with a length of more than $50 \%$. Potential new extent classes for crack related defects might hence be: $0-25 \%, 25-50 \%, 50-75 \%$ and $75-100 \%$ in length of the zone as measured in the direction of the crack.

The current severity codes and definitions in the database can be subjective as it is left up to the inspectors to determine whether a defect is likely to cause damage, poses a danger to the public or causes the element to be non-functional. Opting for severity classes which are defined as e.g. in Table 1 where defect ratings are dependent on measurable properties such as crack widths, depending on the type of reinforcement, can help to overcome this shortcoming. In addition, rating systems do allow for recalibration of the risk assessment if changes are made in the future to the tolerable damage state (as part of an updated asset management strategy).

\section{f. Data gathering - linked photos}

The gathered zonal and crack orientation, severity, extent and width information is numerical and would be readily searchable within a database. However, through additional comments and pictorial evidence, the zonal and crack information also needs to be linked to pictures/photos of the local crack patterns and half-joint overview picture (see item c) since, for example, it is important to understand whether a single crack progresses through several zones or several cracks occur in different zones. As image recognition and searching software continues to develop, sketches and photos will become more readily searchable leading to the potential for crack pattern extraction from images. Hence the inclusion of photographic information would assist with the interpretation of the bridge condition, be a useful cross-check and provide a benchmark for future opportunities for automated digital image comparisons. 


\subsection{Application of zonal method to experimental RC half-joints}

Gathering data in a more systematic way and applying the zonation as described above can lead to a better understanding as well as an added value to inspection results. Common problems, occurring at the same location for several structures can be identified. Furthermore, depending on the reinforcement type (reinforced or pre/post-tensioned), the zonal information can be linked to potential damage causes.

\subsubsection{Application on selected cases within the Highways England asset management database}

Using the zonal approach proposed in the previous section, crack related defects where pictures were provided in the Highways England database, were studied for the selected 23 half-joint structures. In those cases, where the picture allowed, the crack location and orientation could be determined. For a significant number of defects, pictures were not available or were not sufficiently detailed. The zone in which spalling is detected, was identified using the definitions given in Figure 7 and proposed orientations. Cases without an indication of the direction are grouped in 'Unknown'.

Table 6: Location and direction of cracking and spalling related defects for the selected structures (for 62 defects)

\begin{tabular}{|c|c|c|c|c|c|c|}
\hline \multirow[b]{2}{*}{ Direction } & \multicolumn{6}{|c|}{ Zone } \\
\hline & 1 & 2 & 3 & 4 & 5 & 6 \\
\hline $0-20$ degrees & 9 & 2 & 3 & 0 & 0 & 7 \\
\hline $20-70$ degrees & 2 & 2 & 6 & 2 & 1 & 2 \\
\hline 70 - 90 degrees & 3 & 1 & 3 & 1 & 3 & 0 \\
\hline Multiple directions* & 0 & 3 & 3 & 1 & 0 & 0 \\
\hline Unknown** & 3 & 8 & 1 & 2 & 6 & 5 \\
\hline
\end{tabular}

Zones 1 and 6 (zone of compressive reinforcement and tensile reinforcement respectively) often have cracks running at 0 to 20 degrees indicating that they typically coincide with the reinforcement direction. At the inner nib corner (zone 3), cracks occur predominantly at an angle between 20 and 70 degrees (confirming experimental evidence gathered by Desnerck et al 
(Desnerck, Lees and Morley, 2016) on reinforced concrete half-joints). At the nib itself (zone 2), there seems to be no common crack orientation, and cracks are reported in a different direction or even multiple directions for the same half-joint (often running along the other corner). Similar conclusions can be drawn for zone 5 , although there is a tendency for vertical cracks in this region. This case study highlights how a greater insight into the detail about the crack location and orientation can lead to improved decision making about the possible cause, extent and criticality of defects observed. With the caveat that this is a very small sample of data, overall it can be said that the most common location for cracking and/or spalling in the selected half-joints are in region 1 or 6 (along the reinforcement) or in region 3 at the inner nib.

\subsubsection{Application on experimental results from half-joint beams with artificial defects}

The zonal methodology was also applied to reinforced concrete half-joint beam experimental results (Desnerck, Lees and Morley, 2016, 2017b). These studies were designed to investigate the impact of individual as well as combinations of defects/issues which are commonly found in $\mathrm{RC}$ half-joints.

Figure 8 (a) shows the specimens' geometry and reinforcement layout for the reference beam. In addition to the reference beam NS-REF (which was properly designed according to current standards (European Committee for Standardization, 2004)), beams were tested with missing diagonal bars NS-ND, with artificial cracks along the bottom reinforcement (simulating corrosion cracking) combined with improper anchorage of the diagonal bar (LS-PS\&AD\&AL), and with artificial cracks along the bottom bars, improper anchorage of the diagonal bar and a reduced amount of shear reinforcement (LS-PS\&AD\&RS\&AL). Further details on the specimen layouts, test set-up and obtained results, can be found in (Desnerck, Lees and Morley, 2016, 2017b).

For each of the selected experimental beams, the recorded crack pattern at a load of $175 \mathrm{kN}$ ( $\sim 40 \%$ of the failure load of the reference specimen) is shown in Figure $8(b)$. Using the proposed method for inspection and defect recording, the defects were classified for each of these beams (Table 7). Across the four specimens, cracking was noted in zones 3, 4 and 6. 


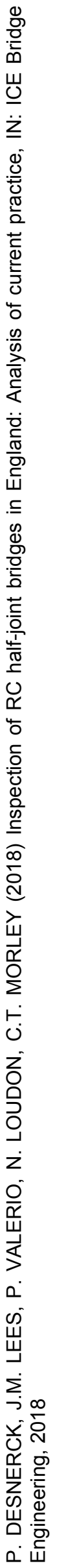

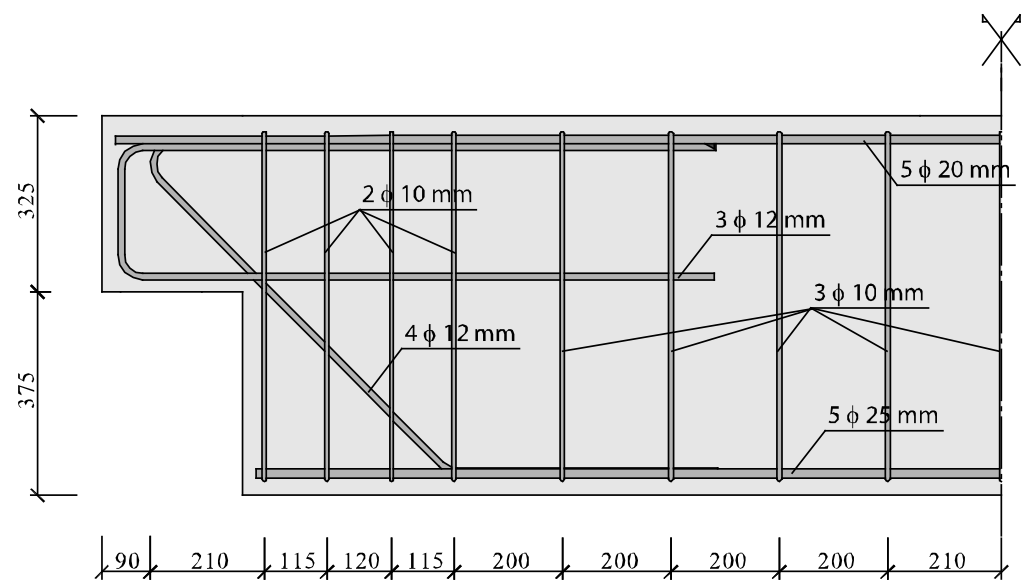

(a)

NS-REF

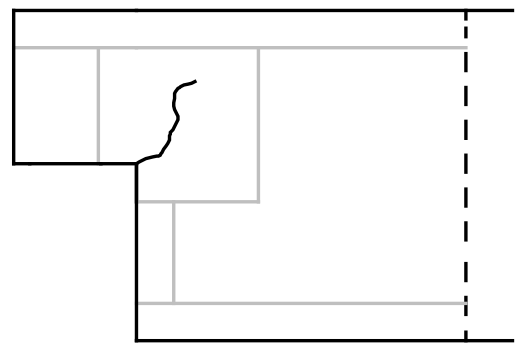

NS-ND

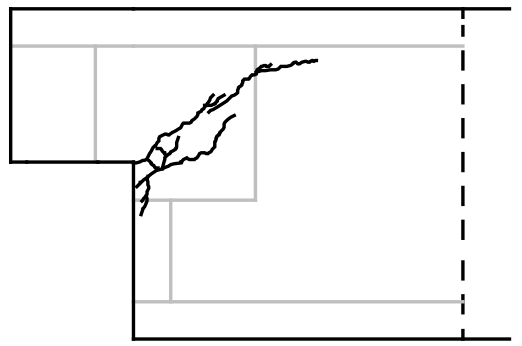

(b)
LS-PS\&AD\&AL

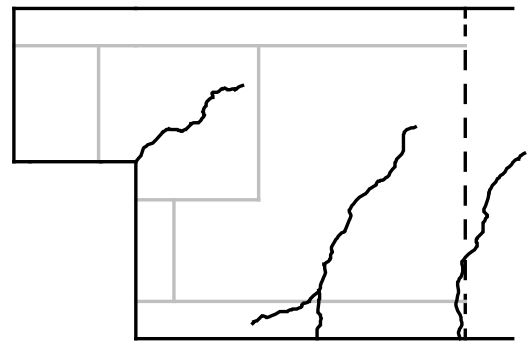

LS-PS\&AD\&RS\&AL

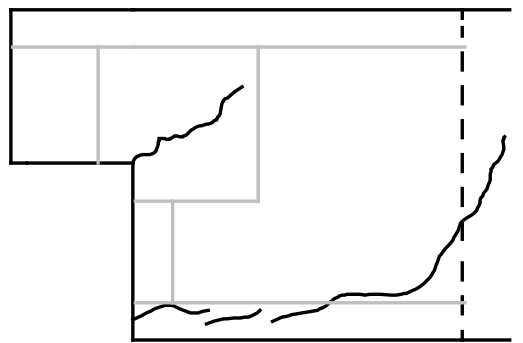

Figure 8: Experimental program: (a) Specimen geometry and reinforcement lay-out, (b) developed crack pattern at $175 \mathrm{kN}$ load mapped to the proposed defect zones 


\begin{tabular}{|c|c|}
\hline Specimen & Defects \\
\hline NS-REF & - Cracked, zone 3, $20-70$ degrees, extent $75-100 \%$ \\
\hline \multirow{2}{*}{ NS-ND } & - Cracked, zone 3, $20-70$ degrees, extent $100 \%$ \\
\hline & - Cracked, zone 4, $20-70$ degrees, extent $0-25 \%$ \\
\hline \multirow{3}{*}{ LS-PS\&AD\&AL } & - Cracked, zone 3, $20-70$ degrees, extent $75-100 \%$ \\
\hline & - Cracked, zone 4, 20 - 70 degrees, extent $75-100 \%$ \\
\hline & - Cracked, zone 6, $0-20$ degrees, extent $0-25 \%$ \\
\hline \multirow{3}{*}{ LS-PS\&AD\&RS\&AL } & - Cracked, zone 3, $20-70$ degrees, extent $75-100 \%$ \\
\hline & - Cracked, zone 4, 0 - 20 degrees, extent $25-50 \%$ \\
\hline & - Cracked, zone 6, 0 - 20 degrees, extent $50-75 \%$ \\
\hline
\end{tabular}

Based on the gathered experimental evidence, the cracks occurring in the different zones can be linked to potential defect types/mechanisms. For the given geometry, reinforcement details and deficiencies of the selected RC half-joint beams, the following interpretations might be developed:

- Zone 3: Vertical as well as inclined cracks, initiated at the inner nib corner, occurred. Inclined cracks were most common and would be reason for concern if the crack opening or crack length is significant (indicating the yield capacity of the inner nib reinforcement has been reached). If the cracks are predominantly vertical, the capacity of the U-bars should be questioned.

- Zone 4: This zone is most vulnerable to shear crack formation and hence it is to be expected that cracks in this zone occur at inclined angles. However, in LSPS\&AD\&RS\&AL there was an indication of horizontal cracks extending into this zone as well.

- Zone 6: The observed cracks in this zone covered a range of indicators whereby the cracks could be orientated horizontally (along the reinforcement) indicating anchorage related issues, vertically which might be due to bending, or inclined which is more likely to be linked to shear.

Although not observed in the experiments reported in Figure 8, for a similar specific RC geometry and reinforcement layout, cracking in other zones could potentially be linked to other deterioration mechanisms/detailing issues. For example: 
- Zone 1 - Cracks in this zone that are orientated horizontally (along the reinforcement) could be indicative of anchorage related issues.

- Zone 2: A likely source of cracks in this zone would be due to corrosion or concrete splitting due to the exceedance of the capacity of the concrete strut which runs from the support to the top compression reinforcement.

- Zone 5: Leakage of chloride rich water into the joint might lead to high chloride diffusion and corrosion of bars in zone 5 .

Sound engineering judgement and due consideration of the particular characteristics of a given structure being assessed or managed remains paramount. However, this case study demonstrates how enriched information can play an important role in interpreting the linkages between inspection findings and structural outcomes.

\subsection{Further developments}

The recommendations to improve data gathering and the inspection of reinforced concrete halfjoints will need to be developed further into a detailed inspection methodology backed with supporting documentation and records. The inspection methodology would need to take into account, amongst other factors, the inspection of other concrete components, the type of inspection (general, principal, special) and the management strategy set out by the asset manager. However, the initial case studies demonstrate how the gathering of additional information within a systematic framework aligned to indicators of half-joint structural issues could significantly improve the quality of the half-joint related defect data. This would allow assessors to more readily identify structures with potential synergistic defects and provide a means for building a more comprehensive picture of the overall state of the half-joints on our road networks. Commonly recurring problems would be more easily identified thereby guiding future research directions and allowing inspectors to pay particular attention to problem locations in existing structures. 


\section{Conclusions}

Bridge management systems play a crucial role in the maintenance of infrastructure assets. Highways England has a long history of using bridge management software to inform decision making. The current asset management tools allow for the storage of structure-related data including inspection history and maintenance activities.

As structures with reinforced concrete half-joints are susceptible to deterioration and are often hard to inspect, they require particular attention. Hence, an Interim Management Strategy was developed to identify all structures on the Highways England road network with half-joint elements and these structures were subjected to a special inspection regime. The data gathered during consecutive inspections was available for further analysis.

An analysis of the asset database indicated that most of England's half-joint structures were built in the late 60 s and 70 s and they can be found all over England. The majority are highway overbridges which are built as pre-tensioned, post-tensioned or reinforced concrete structures. For 252 structures, half-joint related defects are reported. These defects span a variety of different shortcomings. It was shown that most defects could be classified as 'Structural \& Deterioration' or 'Aesthetical'. A clear correlation existed between 'Constructional' and 'Structural \& Deterioration' Defects indicating that construction issues will often lead to more structural defects or enhanced deterioration later in a structures' life. Hence, quality control and proper workmanship during construction are important. The most common half-joint defects were related to corrosion, cracking and spalling.

Corrosion and cracking tend to be reported together and often in combination with spalling, and this was confirmed through a detailed study of a selected subset of structures ( 23 half-joint bridges were randomly picked). Visual inspection remains a subjective process which is highly dependent on the circumstances, skills and experience of bridge inspectors. Several guidelines and standards provide a framework to mitigate this shortcoming. Nevertheless, it was found that e.g. with respect to cracking, some inspectors tend to identify the crack cause by reporting 'shear cracking', 'tension cracking' or 'flexural cracking' (even though pictures did not always confirm this classification) while most inspectors select 'cracks of unknown origin' or 'cracked' defect. 
Given the results from earlier experimental research, an alternative method for gathering halfjoint specific defect data was proposed. This method tries to overcome the shortcoming of a subjective classification of the cracking cause and, concurrently, gather additional insight into the location and orientation of the defect. For selected cases, this approach was applied to half-joint bridge defects where sufficiently detailed pictures were provided. The most common locations for cracking and corrosion turned out to be the inner nib region (zone 3 according to the proposed scheme) and along the compressive and tensile reinforcement (zones 1 and 6). A correlation appeared to exist between crack location and orientation especially in zones 1 and 6 (mostly horizontal cracks along the reinforcement) and in zone 3 (mostly cracks with an inclination around 45 degrees).

Although further development, benchmarking and validation is required, the proposed basis for a methodology to gather half-joint related defect information might allow for the automatic processing and identification of structures with cracks at specific locations (e.g. the inner nib region or along the bottom tensile reinforcement) and flag structures where individual detrimental or synergistic effects (defects occurring at several locations thereby jeopardising the ability of the structure for redistribution of forces) are present. In this way, asset managers will be able to better allocate resources to structures with an increased risk of failure.

\section{Acknowledgements}

The authors would like to acknowledge the financial support of the EPSRC - the Engineering and Physical Sciences Research Council (UK) - through the EPSRC Impact Acceleration Account (IAA) Knowledge Transfer Fellowship 'Impact Acceleration Account - Strategic Roads Network Infrastructure Alliance'.

We are also grateful to Ms S. Sansoa, Mr C. Chaplin, and Mr M. Hill at Highways England for their valuable support and input throughout the project.

Additional data related to this publication is available at the University of Cambridge's institutional data repository. 


\section{References}

ACI Committee 201 (1997) ACl 201.1R-92 Guide for making a condition survey of concrete in service. American Concrete Institute.

ACI Committee 224 (2007) ACI 224.1R-07 Causes, evaluation, and repair of cracks in concrete structures.

Aktan, A. et al. (1996) 'Condition Assessment for Bridge Management', Journal of Infrastructure Systems, 2(3), pp. 108-117.

Collins, J. et al. (2017) RP2905 - Defects in hidden bridge components - Guidance on Detection and Management (Final Draft).

Das, P. C. (1999) 'Development of a Comprehensive Structures Management Methodology for the Highways Agency', in Das, P. C. (ed.) Management of Highway Structures. London, UK: Thomas Telford, pp. 49-60.

Desnerck, P., Lees, J. M. and Morley, C. T. (2016) 'Impact of the reinforcement layout on the load capacity of reinforced concrete half-joints', Engineering Structures, 127, pp. 227-239.

Desnerck, P., Lees, J. M. and Morley, C. T. (2017a) 'Strut-and-tie models for deteriorated reinforced concrete half joints (in press)', Engineering Structures.

Desnerck, P., Lees, J. M. and Morley, C. T. (2017b) 'The effect of local reinforcing bar reductions and anchorage zone cracking on the load capacity of RC half-joints', Engineering Structures, 152, pp. 865-877. doi: 10.1016/j.engstruct.2017.09.021.

Ellswoth, D. E. and Ginnado, K. (1991) Guide for Visual Inspection of Structural Concrete Building Components. Champaign, IL, USA: US Army Corps of Engineers.

Enright, M. and Frangopol, D. (1999) 'Condition Prediction of Deteriorating Concrete bridges using Bayesian Updating', Journal of Structural Engineering, 125(10), pp. 1118-1125.

European Committee for Standardization (2004) EN 1992-1-1 Eurocode 2: Design of concrete structures - Part 1-1: General rules and rules for buildings. European Committee for Standardization.

Gorse, C., Johnston, D. and Pritchard, M. (2012) Oxford Dictionary of Construction, Surveying, and Civil Engineering. USA: Oxford University Press.

Graybeal, B. A. et al. (2002) 'Visual inspection of highway bridges', Journal of Nondestructive Evaluation, 21(3), pp. 67-83.

Highways England (2016a) 'Damaged M20 footbridge to be removed this weekend (Press release)', 2 September.

Highways England (2016b) Highways England - Annual Report and Accounts 2015-2016. Guildford, UK: Highways England.

International Concrete Repair Institute (2015) Concrete Repair Terminology. June 2015. Saint Paul, MN, USA: International Concrete Repair Institute.

Javor, T. (1991) 'Damage classification of concrete structures. The state of the art report of RILEM Technical Committee 104-DCC activity', Materials and Structures, 24(4), pp. 253-259.

Kushida, M., Miyamoto, A. and Kinoshita, K. (1997) 'Development of concrete bridge rating prototype expert system with machine learning', Journal of computing in civil engineering, 11(4), pp. 238-247.

Lauridsen, J. and Lassen, B. (1999) 'The Danish Bridge Management System DANBRO', in The Highways Agency (ed.) Management of Highway Structures. London, UK: Thomas Telford, pp. $61-70$.

Loudon, N. (2004) 'IAN 53/04 - Concrete half-joint deck structures'. Highways England, p. 18. 
McCann, D. and Forde, M. (2001) 'Review of NDT methods in the assessment of concrete and masonry structures', NDT \& E International, 34(2), pp. 71-84.

Mirzaei, Z. et al. (2012) The IABMAS Bridge Managment Committee Overview of Existing Bridge Management Systems. IABMAS.

Patidar, V. et al. (2007) NCHRP Report 590: Multi-Objective Optimization for Bridge Management Systems. Edited by N. C. H. R. Program. Washinton DC, USA: Transportation Research Board.

Phares, B. M. et al. (2004) 'Routine Highway Bridge Inspection Condition Documentation Accuracy and Reliability', Journal of Bridge Engineering, 9(4), pp. 403-413.

SMIS (2016) 'SMIS Half-Joint Dataset'. Highways England.

Soderqvist, M.-K. (1999) 'The Finnish practice and experience regarding bridge inspection and management', in The Highways Agency (ed.) Management of Highway Structures. London, UK: Thomas Telford, pp. 71-80.

Tarighat, A. and Miyamoto, A. (2009) 'Fuzzy concrete bridge deck condition rating method for practical bridge management system', Expert Systems with Applications. Elsevier Ltd, 36(10), pp. 12077-12085.

The Concrete Society (2000) Technical Report No. 54 - Diagnosis of deterioration in concrete structures - Identification of defects, evaluation and development of remedial action.

The Concrete Society (2007) Guidance on the Assessment of Concrete Bridges. Blackwater, UK: Cement and Concrete Industry Publications.

The Highways Agency (1990) BA 35/90 Inspection and Repair of Concrete Highway Structures. London, UK: The Highways Agency.

The Highways Agency (2007a) BD 63/07 - Inspection of Highway Structures. The Highways Agency.

The Highways Agency (2007b) Inspection Manual for Highway Structures. The Stationery Office. 